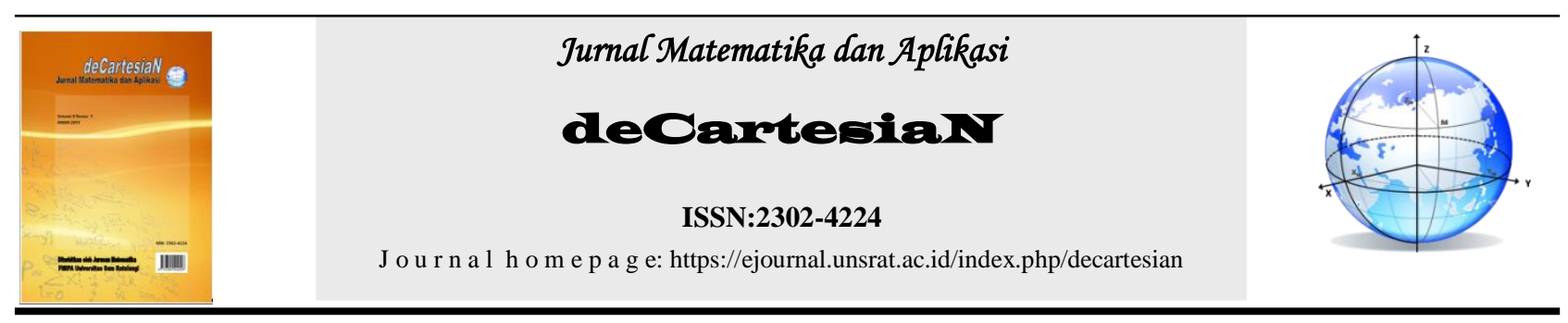

\title{
Fungsi Transposisi Modulo dan Penerapannya Pada Pencarian Susunan Tangga Nada dan Tingkatan Akor
}

\author{
Yuanita Wajongkere ${ }^{1}$, Jullia Titaley ${ }^{1}$, Yohanes A. R. Langi ${ }^{{ }^{*}}$ \\ ${ }^{1}$ Jurusan Matematika-Fakultas Matematika dan Ilmu Pengetahuan Alam-Universitas Sam Ratulangi Manado,Indonesia \\ *Corressponding author : yarlangi@unsrat.ac.id
}

\begin{abstract}
A B S T R A K
Dalam musik, transposisi bertujuan untuk menaik-turunkan nada, nada dasar, dan akor pada sebuah lagu. Penelitian ini bertujuan untuk mencari susunan tangga nada mayor dan minor juga tingkatan akor minor menggunakan fungsi transposisi modulo 12. Data yang digunakan adalah data tentang tangga nada mayor, minor asli, harmonis dan melodis, serta tingkatan akor minor. Setelah ke 12 nada dasar diubah ke bentuk integer model of pitch, dengan memanfaatkan fungsi transposisi $T_{n}(x) \equiv(x+n \bmod 12)$, ditemukan keseluruhan susunan tangga nada dimulai dari tangga nada mayor pada nada dasar C\#, D, D\#, E, F, F\#, G, G\#, A, A\#, dan B. Demikian juga, ditemukan keseluruhan susunan nada pada tangga nada minor asli, harmonis dan melodis untuk setiap nada dasar A\#, B, C, C\#, D, D\#, E, F, F\#, G, dan G\#. Menggunakan fungsi transposisi yang sama, untuk $x$ himpunan akor minor natural, harmonis dan melodis, ditemukan tingkatan akor minor lainnya mulai dari tingkatan akor minor asli/natural baik dari tingkatan ke I sampai tingkatan ke VII pada setiap akor dasar A\#m, Bm, Cm, C\#m, Dm, D\#m, Em, Fm, F\#m, Gm, dan G\#m. Demikian juga untuk tingkatan akor harmonis dan melodis didapat keseluruhan tingkatan akor mulai dari akor dasar A\#mM7, BmM7, $\mathrm{CmM}_{7}, \mathrm{C} \# \mathrm{mM}_{7}, \mathrm{DmM}_{7}, \mathrm{D} \# \mathrm{Mm}_{7}, \mathrm{EmM}_{7}$, $\mathrm{FmM}_{7}, \mathrm{~F} \# \mathrm{mM} 7, \mathrm{GmM} 7$, dan G\#mM7. Hal ini penting agar lebih memudahkan seorang pemusik dalam memainkan melodi dan akor-akor penyusun sebuah lagu, bila nada dasarnya berpindah menjadi lebih tinggi atau rendah. Begitu juga sang penyanyi akan lebih mudah untuk menentukan nada dasar yang cocok pada sebuah lagu yang akan dinyanyikan sesuai dengan keinginan penyanyi.
\end{abstract}

\author{
INFO ARTIKEL \\ Diterima : 11 Desember 2018 \\ Tersedia online: 31 Januari 2019 \\ Kata Kunci: \\ Fungsi Transposisi Modulo \\ Tangga Nada Mayor \\ Tangga Nada Minor \\ Tingkatan Akor Minor \\ Integer Model Of Pitch
}

Diterima setelah revisi : 29 Januari 2019

\section{PENDAHULUAN}

Matematika berkaitan erat dengan seni musik. Bahkan para ahli matematika pun menyukai bahkan berbakat dalam bidang musik seperti Pythagoras yang adalah seorang pemain lira, dan George Cantor yang merupakan pecinta musik serta Democritus matematikawan Yunani yang juga menjadi pelopor untuk mempelajari teori musik. Ada banyak penelitian yang menemukan hubungan yang erat antara matematika dan musik. Misalnya, penerapan dimensi fraktal untuk klasifikasi laras pada musik gamelan dengan menggunakan metode Highuci [5]. Terdapat pengaruh yang signifikan, musik klasik terhadap hasil dan aktivitas belajar matematika siswa [2]. Matematika dan musik juga memiliki keterkaitan yang erat dalam penentuan tangga nada dan akor pada sebuah lagu yang akan dinyanyikan oleh seseorang. Pada dasarnya jenis suara manusia dibedakan menjadi menjadi soprano, mezzo soprano, dan alto pada suara wanita dewasa, dan tenor, bariton dan bass pada suara pria dewasa. Dalam menyanyikan sebuah lagu, jenis suara merupakan pertimbangan yan sangat penting. Seorang alto dengan wilayah suara $\mathrm{F}_{3}-\mathrm{F}_{5}$ akan merasa sulit menyanyi bila lagu yang akan dinyanyikan jangkauan nadanya berada di wilayah suara soprano yaitu yang memiliki wilayah suara dari C4-C6. Begitu juga dengan seorang pria akan merasa sulit ataupun tidak bisa menyanyikan lagu dengan jangkauan nadanya berada di wilayah suara wanita. Persoalan seperti ini bisa diatasi dengan mentransposisi akor atau nada dasar pada lagu. Dalam seni musik, transposisi mengacu pada perubahan tangga nada atau akor menjadi lebih rendah atau lebih tinggi. Penelitian ini mengkaji tentang pencarian susunan tangga nada mayor dan minor dan tingkatan akor minor menggunakan rumus fungsi transposisi modulo 12 yang akan lebih memudahkan dalam menentukan nada dasar sebuah lagu.

\section{TINJAUAN PUSTAKA}

\subsection{Fungsi Modulo (Aritmetika Modulo)}

Misalkan a adalah bilangan bulat dan $\mathrm{m}$ adalah bilangan bulat > o. Operasi a $\bmod m$ (dibaca "a modulo m") memberikan sisa jika a dibagi dengan $\mathrm{m}$. Notasi: $a \bmod m=r$ sedemikian sehingga $a=m q+r$, dengan $\mathrm{o} r<\mathrm{m}$. Bilangan $\mathrm{m}$ disebut modulus atau modulo, dan hasil aritmetika modulo $m$ terletak di dalam himpunan $\{0,1,2, \ldots, m-1\}$. (Grillet, 2007).

Beberapa hasil operasi dengan operator modulo :

$23(\bmod 5)=3 \quad(23=5 \times 4+3)$

$27(\bmod 3)=0 \quad(27=3 \times 9+0)$ 


\subsection{Rumus Fungsi Transposisi}

Dalam seni musik, transposisi mengacu pada perubahan tangga nada atau akor menjadi lebih rendah atau lebih tinggi. Sedangkan dalam matematika transposisi dapat didefinisikan sebagai fungsi modulo .

Definisi :

Misalkan $n$ adalah bilangan bulat modulo 12 maka fungsi $T_{n}: \mathbb{Z}_{12} \rightarrow \mathbb{Z}_{12}$ didefinisikan dengan rumus

$$
T_{n}(x) \equiv(x+n(\bmod 12))[1]
$$

yang mana $\mathbb{Z}_{12}$ himpunan bilangan bulat $n$ modulo 12 . Keterangan:

$n=0,1,2,3,4,5, \ldots ., 11$

$x=$ anggota himpunan trinada dalam akor atau himpunan nada-nada pada tangga nada

$\mathbb{Z}_{12}$ adalah bilangan bulat pada nada modulo 12 yang digunakan oleh musisi dan matematikawan. Atau sering disebut the set of integer mod 12.

\subsection{Tangga Nada Diatonis Mayor}

Tangga nada diatonis mayor adalah susunan nada-nada yang mempunyai jarak 1 semitone pada nada ke $3-4$, dan ke $7-1$ (oktaf), dan jarak nadanada yang lain adalah 1 tone (whole-tone). Tangga nada mayor natural adalah tangga nada mayor yang seluruh nada-nadanya belum mengalami perubahan. Susunan tangga nada mayor yang belum mengalami perubahan (natural), merupakan nada-nada papan putih pada alat musik piano (keyboard).

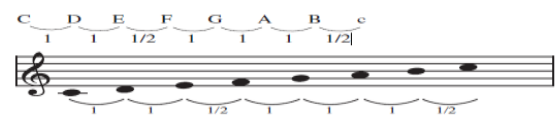

Gambar 1. Tangga Nada Diatonis Mayor Natural

Oleh karena tangga nada tersebut dimulai dari C (sebagai tonika), maka tangga nada mayor natural disebut juga tangga nada $\mathrm{C}$ Mayor $(\mathrm{C}=\mathrm{do})$.

Tabel 1. Susunan Tangga Nada Diatonis Mayor

\begin{tabular}{|c|c|c|c|c|c|c|c|c|c|}
\hline Tanda & Nada & \multicolumn{8}{|c|}{ SUSUNAN NADA } \\
\hline Natural & $\mathrm{C}$ & $\mathrm{C}$ & $\mathrm{D}$ & $\mathrm{E}$ & $\mathrm{F}$ & $\mathrm{G}$ & A & $\mathrm{B}$ & $\mathrm{C}$ \\
\hline \multicolumn{2}{|c|}{ Interval nada } & \multicolumn{3}{|c|}{$1 \quad 1$} & \multicolumn{2}{|c|}{1} & \multicolumn{2}{|c|}{1} & \\
\hline \multicolumn{2}{|c|}{ Notasi angka } & 1 & 2 & 3 & 4 & 5 & 6 & 7 & i \\
\hline \multicolumn{2}{|c|}{ Solmisasi } & Do & $\operatorname{Re}$ & Mi & $\mathrm{Fa}$ & Sol & $\mathrm{La}$ & $\mathrm{Ti}$ & Do \\
\hline
\end{tabular}

\subsection{Tangga Nada Diatonis Minor}

Tangga nada minor adalah salah satu tangga nada diatonik. Tangga nada ini tersusun oleh delapan not. Tangga nada minor dapat dilihat sebagai mode musik keenam dalam tangga nada mayor. Tangga nada minor kadangkala dianggap mempunyai bunyi yang cenderung lebih sedih dibandingkan dengan tangga nada mayor.

\section{a. Tangga Nada Minor Asli}

Tangga nada minor asli adalah tangga nada minor yang nada ke $2-3$, dan ke $5-6$ mempunyai jarak 1 semitone, dan jarak antara nada nada yang lain 1 tone (whole-tone). Sehingga nada-nada yang tersusun dalam tangganada minor asli natural (tn. a minor asli), adalah : $\mathrm{a}-\mathrm{b}-\mathrm{c}-\mathrm{d}-\mathrm{e}-\mathrm{f}-\mathrm{g}-\mathrm{a}$ :

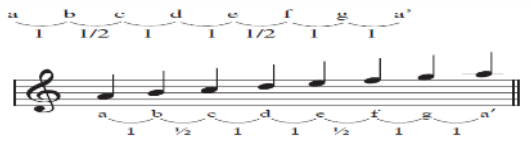

Gambar 4. Tangga nada diatonis minor natural

Tabel 2. Susunan Tangga Nada Minor Asli

\begin{tabular}{|c|c|c|c|c|c|c|c|c|c|}
\hline $\begin{array}{c}\text { Tanda } \\
\text { mula }\end{array}$ & $\begin{array}{c}\text { Nada } \\
\text { dasar }\end{array}$ & \multicolumn{10}{|c|}{ SUSUNAN NADA } \\
\hline Natural & Am & A & B & C & D & E & F & G & A \\
\hline Interval nada & \multicolumn{1}{|c|}{1} & $\frac{1}{2}$ & 1 & 1 & $\frac{1}{2}$ & 1 & 1 \\
\hline Notasi angka & 6 & 7 & i & $\dot{2}$ & $\dot{3}$ & $\dot{4}$ & $\dot{5}$ & $\dot{6}$ \\
\hline Solmisasi & La & Ti & Do & Re & Mi & Fa & Sol & La \\
\hline
\end{tabular}

\section{b. Tangga Nada Minor Harmonis}

Tangga nada minor harmonis adalah tangga nada minor asli, yang nada ke-7 nya dinaikkan 1 semitone. Sehingga nada-nada yang tersusun dalam tangga nada minor harmonis natural (tn. a m harmonis), adalah : a $-b-c-d-e-f-$ gis $-a$.

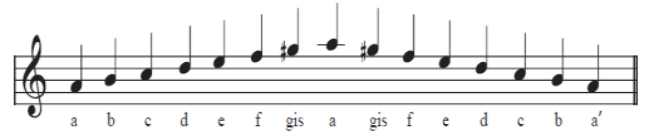

Gambar 4. Tangga nada diatonis minor harmonis

Tabel 3. Susunan Tangga Nada Minor Harmonis

\begin{tabular}{|c|c|c|c|c|c|c|c|c|c|}
\hline $\begin{array}{c}\text { Tanda } \\
\text { mula }\end{array}$ & $\begin{array}{c}\text { Nada } \\
\text { dasar }\end{array}$ & \multicolumn{10}{|c|}{ SUSUNAN NADA } \\
\hline Harmonis & Am & A & B & C & D & E & Fis & G & A \\
\hline Interval nada & \multicolumn{2}{|c|}{1} & $\frac{1}{2}$ & 1 & 1 & 1 & $\frac{1}{2}$ & 1 \\
\hline Notasi angka & 6 & 7 & 1 & $\dot{2}$ & $\dot{3}$ & $\dot{4}$ & $\dot{5}$ & $\dot{6}$ \\
\hline Solmisasi & La & Ti & Do & Re & Mi & Fa & Sol & La \\
\hline
\end{tabular}

\section{c. Tangga Nada Minor Melodis}

Tangga nada minor melodis adalah tangga nada minor asli, yang nada ke-6 dan nada ke-7 nya dinaikkan 1 semitone untuk naik / ascending, dan kembali natural untuk turun / descending. Sehingga nada-nada yang tersusun dalam tangga nada minor melodis natural (tn. a minor melodis), adalah : $\mathrm{a}-\mathrm{b}-$ $\mathrm{c}-\mathrm{d}-\mathrm{e}-$ fis - gis $-\mathrm{a}-\mathrm{g}-\mathrm{f}-\mathrm{e}-\mathrm{d}-\mathrm{c}-\mathrm{b}-\mathrm{a}$

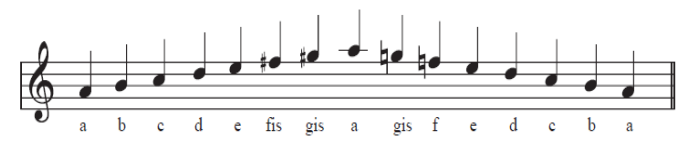

Gambar 5. Tangga Nada Diatonis Minor Melodis 
Fungsi Transposisi Modulo dan Penerapannya Pada Pencarian Susunan Tangga Nada dan Tingkatan Akor Jurnal Matematika dan Aplikasi dan Aplikasi deCartesiaN, Vol.8, No.1 (Maret 2019): 11-17

Tabel 4. Susunan Tangga Nada Melodis Naik

\begin{tabular}{|c|c|c|c|c|c|c|c|c|c|}
\hline $\begin{array}{c}\text { Tanda } \\
\text { mula }\end{array}$ & $\begin{array}{l}\text { Nada } \\
\text { dasar }\end{array}$ & \multicolumn{8}{|c|}{ SUSUNAN NADA } \\
\hline $\begin{array}{c}\text { Melodis } \\
\text { naik }\end{array}$ & Am & A & B & $\mathrm{C}$ & $\mathrm{D}$ & $\mathrm{E}$ & Fis & Gis & A \\
\hline \multicolumn{2}{|c|}{ Interval nada } & \multicolumn{2}{|c|}{1} & $\frac{1}{2}$ & & \multicolumn{2}{|c|}{1} & \multicolumn{2}{|c|}{$\overline{2}$} \\
\hline \multicolumn{2}{|c|}{ Notasi angka } & 6 & 7 & i & $\dot{2}$ & $\dot{3}$ & $\dot{4}$ & $\dot{5}$ & $\dot{6}$ \\
\hline \multicolumn{2}{|c|}{ Solmisasi } & $\mathrm{La}$ & $\mathrm{Ti}$ & Do & $\operatorname{Re}$ & $\mathrm{Mi}$ & $\mathrm{Fa}$ & Sol & $\mathrm{La}$ \\
\hline
\end{tabular}

\subsection{Tingkatan Akor}

Sama seperti nama-nama tingkatan nada dalam sebuah tangga nada, triad/akor juga mempunyai nama-nama tingkatannya, yaitu :

$$
\begin{array}{ll}
\text { I } & \text { : tonika } \\
\text { II } & : \text { supertonik } \\
\text { III } & : \text { median } \\
\text { IV } & : \text { subdominan } \\
\text { V } & : \text { dominan } \\
\text { VI } & : \text { submedian } \\
\text { VII } & \text { : leadingtone }
\end{array}
$$

Akor tonika, subdominan, dan dominan, dalam tangga nada mayor adalah akor-akor berkualitas mayor, dan akor supertonika, median, dan submedian, adalah akor-akor berkualitas minor. Sedangkan akor leadingtone, berkualitas diminished. Dalam tangga nada minor harmonis, akor tonika, dan subdominan, adalah akor-akor berkualitas minor, dan akor dominan, dan akor submedian, adalah akor-akor berkualitas mayor. Sedangkan akor leadingtone, berkualitas diminished.

\section{a. Tingkatan Akor Diatonis Mayor}

Dalam tangga nada mayor, tingkatan akornya adalah sebagai berikut [4] :

Tabel 5. Tingkatan Akor Diatonis Mayor

\begin{tabular}{|c|c|c|c|}
\hline $\begin{array}{c}\text { Tingkat } \\
\text { Akor }\end{array}$ & $\begin{array}{c}\text { Nama } \\
\text { Tingkatan } \\
\text { Akor }\end{array}$ & Akor & Keterangan \\
\hline I & Tonika & C-E-G & C Mayor \\
\hline II & Supertonika & D-F-A & d minor \\
\hline III & Median & E-G-B & e minor \\
\hline IV & Subdominan & F-A-C & F Mayor \\
\hline V & Dominan & G-B-D & G Mayor \\
\hline VI & Submedian & A-C-E & a minor \\
\hline VII & Leading tone & B-D-F & B dimished \\
\hline
\end{tabular}

\section{b. Tingkatan Akor Diatonis Minor Asli}

Tabel 6. Tingkatan Akor Diatonis Minor Asli

\begin{tabular}{|c|c|c|c|}
\hline $\begin{array}{c}\text { Tingkat } \\
\text { Akor }\end{array}$ & $\begin{array}{c}\text { Nama } \\
\text { Tingkatan } \\
\text { Akor }\end{array}$ & Akor & Keterangan \\
\hline I & Tonika & A-C-E & A minor \\
\hline II & Supertonika & B-D-F & B dimished \\
\hline III & Median & C-E-G & C Mayor \\
\hline IV & Subdominan & D-F-A & D minor \\
\hline V & Dominan & E-G-B & E minor \\
\hline VI & Submedian & F-A-C & F Mayor \\
\hline VII & Leading tone & G-B-D & G Mayor \\
\hline \multicolumn{4}{r}{} \\
\end{tabular}

\section{c. Tingkatan Akor Diatonis Minor Harmonis}

Tabel 7. Tingkatan Akor Diatonis Minor Harmonis

\begin{tabular}{|c|c|c|c|}
\hline $\begin{array}{c}\text { Tingkat } \\
\text { Akor }\end{array}$ & $\begin{array}{c}\text { Nama } \\
\text { Tingkatan } \\
\text { Akor }\end{array}$ & Akor & Keterangan \\
\hline I & Tonika & A-C-E-G\# & AmM7 \\
\hline II & Supertonika & B-D-F-A & Bm7b5 \\
\hline III & Median & C-E-G\#-B & CM7\#5 \\
\hline IV & Subdominan & D-F-A-C & Dm7 \\
\hline V & Dominan & E-G\#-B-D & E7 \\
\hline VI & Submedian & F-A-C-E & FM7 \\
\hline VII & Leading tone & G\#-B-D-F & G\#dim7 \\
\hline
\end{tabular}

\section{d. Tingkatan Akor Diatonis Minor Melodis}

Tabel 8. Tingkatan Akor Diatonis Minor Melodis

\begin{tabular}{|c|c|c|c|}
\hline $\begin{array}{c}\text { Tingkat } \\
\text { Akor }\end{array}$ & $\begin{array}{c}\text { Nama } \\
\text { Tingkatan } \\
\text { Akor }\end{array}$ & Akor & Keterangan \\
\hline I & Tonika & A-C-E-G\# & AmM7 \\
\hline II & Supertonika & B-D-F\#-A & Bm7 \\
\hline III & Median & C-E-G\#-B & CM7\#5 \\
\hline IV & Subdominan & D-F\#-A-C & D7 \\
\hline V & Dominan & E-G\#-B-D & E7 \\
\hline VI & Submedian & F\#-A-C-E & F\#m7b5 \\
\hline VII & Leading tone & G\#-B-D-F\# & G\#m7b5 \\
\hline
\end{tabular}

\section{METODOLOGI PENELITIAN}

\subsection{Data}

Data yang digunakan dalam penelitian ini adalah data sekunder yaitu data tentang tangga nada dan tingkatan akor mayor dan minor. Teknik pengumpulan data yang digunakan dalam skripsi ini adalah teknik dokumenter atau studi literatur.

\subsection{Prosedur Penelitian}

Adapun prosedur yang akan dilakukan dalam penelitian ini adalah sebagai berikut :

1. Mengubah 12 nada kromatik mayor dan minor ke bentuk integer model of pitch.

2. Menentukan rumus fungsi transposisi pada pencarian susunan tangga nada.

3. Menerapkan rumus fungsi transposisi nada pada pencarian susunan tangga nada.

4. Menentukan rumus fungsi transposisi pada pencarian tingkatan akor

5. Menerapkan rumus fungsi transposisi akor pada pencarian tingkatan akor

\section{HASIL DAN PEMBAHASAN}

\subsection{Mencari Susunan Tangga Nada Mayor}

Dalam musik ada 12 macam nada, untuk itu ke-12 macam nada ini diubah kedalam bilangan bulat, dimana bilangan bulat tersebut $\geq 0$ dan $<12$. Nada tersebut diubah agar dapat diterapkan aritmatika modulo. Hal ini disebut dengan integer model of pitch. 
Tabel 9. Konversi Nada Pada Bilangan Bulat

\begin{tabular}{|c|c|}
\hline Nada & $\begin{array}{c}\text { Bilangan } \\
\text { bulat }\end{array}$ \\
\hline $\mathrm{C}$ & 0 \\
\hline $\mathrm{C} \# / \mathrm{Db}$ & 1 \\
\hline $\mathrm{D}$ & 2 \\
\hline $\mathrm{D} \# / \mathrm{Eb}$ & 3 \\
\hline $\mathrm{E}$ & 4 \\
\hline $\mathrm{F}$ & 5 \\
\hline $\mathrm{F} \# / \mathrm{Gb}$ & 6 \\
\hline $\mathrm{G}$ & 7 \\
\hline $\mathrm{G} \# / \mathrm{Ab}$ & 8 \\
\hline $\mathrm{A}$ & 9 \\
\hline $\mathrm{A} \# / \mathrm{Bb}$ & 10 \\
\hline $\mathrm{B}$ & 11 \\
\hline
\end{tabular}

Berdasarkan Tabel 1, susunan tangga nada diatonis mayor natural $(\mathrm{C}=\mathrm{do})$ setelah dikonversikan ke bilangan bulat menjadi :

$$
0-2-4-5-7-9-11-0
$$

Fungsi transposisi untuk mencari susunan tangga nada mayor adalah:

Dengan :

$$
\mathrm{T}_{\mathrm{n}} \mathrm{x} \equiv(\mathrm{x}+\mathrm{n}(\bmod 12))
$$

$\mathrm{n}=0,1,2,3,4, \ldots, 11$

$\mathrm{x}=$ himpunan nada-nada tangga nada mayor natural Menggunakan fungsi transposisi, transposisi nada berdasarkan tangga nada mayor natural didapat :

Tabel. 10 Susunan Tangga Nada untuk Semua Nada Dasar Mayor

\begin{tabular}{|c|c|}
\hline NADA DASAR & SUSUNAN NADA \\
\hline C & C-D-E-F-G-A-B-C \\
\hline C\#/Db & C\#-D\#-F-F\#-G\#-A\#-C-C\# \\
\hline D & D-E-F\#-G-A-B-C\#-D \\
\hline D\#/Eb & D\#-F-G-G\#-A\#-C-D-D\# \\
\hline E & E-F\#-G\#-A-B-C\#-D\#-E \\
\hline F & F-G-A-A\#-C-D-E-F \\
\hline F\#/Gb & F\#-G\#-A\#-B-C\#-D\#-F-F\# \\
\hline G & G-A-B-C-D-E-F\#-G \\
\hline G\#/Ab & G\#-A\#-C-C\#-D\#-F-G-G\# \\
\hline A & A-B-C\#-D-E-F\#-G\#-A \\
\hline A\#/Bb & A\#-C-D-D\#-F-G-A-A\# \\
\hline B & B-C\#-D\#-E-F\#-G\#-A\#-B \\
\hline
\end{tabular}

\subsection{Mencari Susunan Tangga Nada Minor}

Sama seperti pada tangga nada mayor, tangga nada minor dapat dikonversikan ke bilangan bulat, menjadi :

Tabel. 11 Konversi Nada Pada Bilangan Bulat

\begin{tabular}{|c|c|}
\hline Nada & Bilangan bulat \\
\hline $\mathrm{A}$ & $\mathrm{O}$ \\
\hline $\mathrm{A} \# / \mathrm{Bb}$ & 1 \\
\hline $\mathrm{B}$ & 2 \\
\hline $\mathrm{C}$ & 3 \\
\hline $\mathrm{C} \# / \mathrm{Db}$ & 4 \\
\hline $\mathrm{D}$ & 5 \\
\hline $\mathrm{D} \# / \mathrm{Eb}$ & 6 \\
\hline $\mathrm{E}$ & 7 \\
\hline $\mathrm{F}$ & 8 \\
\hline $\mathrm{F} \# / \mathrm{Gb}$ & 9 \\
\hline $\mathrm{G}$ & 10 \\
\hline $\mathrm{G} \# / \mathrm{Ab}$ & 11 \\
\hline
\end{tabular}

Fungsi transposisi untuk mencari susunan tangga nada minor adalah:

Dengan :

$$
\mathrm{T}_{\mathrm{n}} \mathrm{x} \equiv(\mathrm{x}+\mathrm{n}(\bmod 12))
$$

$\mathrm{n}=0,1,2,3,4, \ldots, 11$

$\mathrm{x}=$ himpunan nada-nada tangga nada minor

\section{a. Mencari Susunan Tangga Nada Diatonis Minor Asli}

Berdasarkan Tabel 2, susunan tangga nada diatonis minor asli setelah dikonversikan ke bilangan bulat menjadi :

$$
0-2-3-5-7-8-10-0
$$

Dengan menggunakan fungsi transposisi, susunan tangga nada minor asli adalah sebagai berikut:

Tabel. 12 Susunan Tangga Nada untuk Semua Nada

\begin{tabular}{|c|c|}
\multicolumn{1}{c|}{ Dasar Minor Asli } \\
\hline NADA DASAR & SUSUNAN NADA \\
\hline A & A-B-C-D-E-F-G-A \\
\hline A\#/Bb & A\#-C-C\#-D\#-F-F\#-G\#-A\# \\
\hline B & B-C\#-D-E-F\#-G-A-B \\
\hline C & C-D-D\#-F-G-G\#-A\# \\
\hline C\#/Db & C\#-D\#-E-F\#-G\#-A-B-C\# \\
\hline D & D-E-F-G-A-A\#-C-D \\
\hline D\#/Eb & D\#-F-F\#-G\#-A\#-B-C\#-D\# \\
\hline E & E-F\#-G-A-B-C-D-E \\
\hline F & F-G-G\#-A\#-C-C\#-D\#-F \\
\hline F\#/Gb & F\#-G\#-A-B-C\#-D-E-F\# \\
\hline G & G-A-A\#-C-D-D\#-F-G \\
\hline G\#/Ab & G\#-A\#-B-C\#-D\#-E-F\#-G\# \\
\hline
\end{tabular}

\section{b. Mencari Susunan Tangga Nada Diatonis Minor Harmoni}

Berdasarkan Tabel 3 susunan tangga nada diatonis minor harmoni setelah dikonversikan ke bilangan bulat menjadi :

$$
0-2-3-5-7-8-11-0
$$

Dengan menggunakan fungsi transposisi, susunan lengkap tangga nada minor harmoni adalah sebagai berikut:

Tabel 13. Susunan Tangga Nada untuk Semua Nada Dasar Minor Harmonis

\begin{tabular}{|c|c|}
\hline NADA DASAR & SUSUNAN NADA \\
\hline A & A-B-C-D-E-F-G\#-A \\
\hline A\#/Bb & A\#-C-C\#-D\#-F-F\#-A-A\# \\
\hline B & B-C\#-D-E-F\#-G-A\#-B \\
\hline C & C-D-D\#-F-G-G\#-B-C \\
\hline C\#/Db & C\#-D\#-E-F\#-G\#-A-C-C\# \\
\hline D & D-E-F-G-A-A\#-C\#-D \\
\hline D\#/Eb & D\#-F-F\#-G\#-A\#-B-D-D\# \\
\hline E & E-F\#-G-A-B-C-D\#-E \\
\hline F & F-G-G\#-A\#-C-C\#-E-F \\
\hline F\#/Gb & F\#-G\#-A-B-C\#-D-F-F\# \\
\hline G & G-A-A\#-C-D-D\#-F\#-G \\
\hline G\#/Ab & G\#-A\#-B-C\#-D\#-E-G-G\# \\
\hline
\end{tabular}

\section{c. Mencari Susunan Tangga Nada Diatonis Minor Melodis}

Berdasarkan Tabel 4 susunan tangga nada diatonis minor melodis setelah dikonversikan ke bilangan bulat menjadi : 
Fungsi Transposisi Modulo dan Penerapannya Pada Pencarian Susunan Tangga Nada dan Tingkatan Akor Jurnal Matematika dan Aplikasi dan Aplikasi deCartesiaN, Vol.8, No.1 (Maret 2019): 11-17

$0-2-3-5-7-9-11-0$

Dengan menggunakan fungsi transposisi, susunan lengkap tangga nada minor Asli adalah sebagai berikut:

Tabel. 14 Susunan Tangga Nada untuk Semua Nada Dasar Minor Melodis

\begin{tabular}{|c|c|}
\hline NADA DASAR & SUSUNAN NADA \\
\hline A & A-B-C-D-E-F-G\#-A \\
\hline A\#/Bb & A\#-C-C\#-D\#-F-G-A-A\# \\
\hline B & B-C\#-D-E-F\#-G\#-A\#-B \\
\hline C & C-D-D\#-F-G-A-B-C \\
\hline C\#/Db & C\#-D\#-E-F\#-G\#-A\#-C-C\# \\
\hline D & D-E-F-G-A-B-C\#-D \\
\hline D\#/Eb & D\#-F-F\#-G\#-A\#-C-D-D\# \\
\hline E & E-F\#-G-A-B-C\#-D\#-E \\
\hline F & F-G-G\#-A\#-C-D-E-F \\
\hline F\#/Gb & F\#-G\#-A-B-C\#-D\#-F-F\# \\
\hline G & G-A-A\#-C-D-E-F\#-G \\
\hline G\#/Ab & G\#-A\#-B-C\#-D\#-F-G-G\# \\
\hline
\end{tabular}

Berdasarkan hasil tersebut, terdapat masingmasing 12 susunan nada dasar pada tangga nada mayor, minor asli, minor harmonis, dan minor melodis, yang nantinya akan memudahkan seorang pemusik menentukan melodi yang akan dimainkan berdasarkan susunan nada dasar tersebut.

Selanjutnya akan dibahas tentang pencarian susunan tingkatan akor. Sebelumnya telah dikaji tentang penerapan fungsi transposisi akor dalam mencari akor-akor penyusun sebuah lagu pada tangga nada mayor dengan C Mayor sebagai akor dasar [3]. Dan pada kajian kali ini, akan dibahas tentang penerapan fungsi transposisi akor pada pencarian tingkatan akor tangga nada minor, baik pada tangga nada minor asli, harmonis, dan melodis.

\subsection{Mencari Tingkatan Akor Minor}

Fungsi transposisi untuk mencari tingkatan akor minor adalah :

Dengan :

$$
\mathrm{T}_{\mathrm{n}} \mathrm{x} \equiv(\mathrm{x}+\mathrm{n}(\bmod 12))
$$

$\mathrm{n}=0,1,2,3,4, \ldots, 11$

$\mathrm{x}=$ himpunan akor skala minor

\section{a. Pencarian Tingkatan Akor Minor Tangga Nada Minor Asli \\ Berdasarkan Tabel 9 tingkatan akor minor asli} adalah :

Am-Bdim-CM-Dm-Em-FM-GM

Menggunakan fungsi transposisi akor diperoleh :
Tabel 15. Tingkatan Akor untuk Semua Akor Dasar Minor Asli

\begin{tabular}{|c|c|c|c|c|c|c|c|}
\hline $\begin{array}{c}\text { NAMA } \\
\text { AKOR } \\
\text { (DASAR) }\end{array}$ & \multicolumn{5}{|c|}{ TINGKATAN AKOR MINOR ASLI } \\
\cline { 2 - 8 } & II & III & IV & V & VI & VII \\
\hline A\#m & Am & Bdim & CM & Dm & Em & FM & GM \\
\hline Bm & Bm & C\#dim & C\#M & D\#m & Fm & F\#M & G\#M \\
\hline Cm & Cm & Ddim & D\#M & Fm & Gm & G\#M & A\#M \\
\hline C\#m & C\#m & D\#dim & EM & F\#m & G\#m & AM & BM \\
\hline Dm & Dm & Edim & FM & Gm & Am & A\#M & CM \\
\hline D\#m & D\#m & Fdim & F\#M & G\#m & A\#m & BM & C\#M \\
\hline E & E & F\#dim & GM & Am & Bm & CM & DM \\
\hline Fm & Fm & Gdim & G\#M & A\#m & Cm & C\#M & D\#M \\
\hline F\#m & F\#m & G\#dim & AM & Bm & C\#m & DM & EM \\
\hline Gm & Gm & Adim & A\#M & Cm & Dm & D\#M & FM \\
\hline G\#m & G\#m & A\#dim & BM & C\#m & D\#m & EM & F\#M \\
\hline
\end{tabular}

b. Pencarian Tingkatan Akor Minor Tangga Nada Minor Harmonis

Berdasarkan Tabel 10 tingkatan akor minor harmonis adalah :

AmM7-Bm7b5-CM7\#5-Dm7-E7-FM7-G\#dim7

Menggunakan fungsi transposisi akor maka didapat :

Tabel 16. Tingkatan Akor untuk Semua Akor Dasar Minor Harmonis

\begin{tabular}{|c|c|c|c|c|c|c|c|}
\hline \multirow{2}{*}{$\begin{array}{c}\text { NAMA } \\
\text { AKOR } \\
\text { (DASAR) }\end{array}$} & \multicolumn{7}{|c|}{ TINGKATAN AKOR MINOR HARMONIS } \\
\hline & I & II & III & IV & $\mathrm{V}$ & VI & VII \\
\hline $\mathrm{AmM}_{7}$ & $\mathrm{AmM}_{7}$ & Bm7b5 & $\mathrm{CM}_{7 \# 5}$ & Dm7 & E7 & $\mathrm{FM}_{7}$ & $\mathrm{G} \# \operatorname{dim} 7$ \\
\hline $\mathrm{A} \# \mathrm{mM} 7$ & $\mathrm{~A} \# \mathrm{mM} 7$ & Cm7b5 & $\mathrm{C} \# \mathrm{M} 7 \# 5$ & $\mathrm{D} \# \mathrm{~m} 7$ & $\mathrm{~F} 7$ & $\mathrm{~F} \# \mathrm{M} 7$ & $\mathrm{G} \# \operatorname{dim} 7$ \\
\hline $\mathrm{BmM}_{7}$ & $\mathrm{BmM}_{7}$ & $\mathrm{C} \# \mathrm{~m} 7 \mathrm{~b} 5$ & $\mathrm{DM} 7 \# 5$ & Em7 & $\mathrm{F} \# 7$ & $\mathrm{GM}_{7}$ & Adim7 \\
\hline $\mathrm{CmM}_{7}$ & $\mathrm{CmM}_{7}$ & Dm7b5 & $\mathrm{D} \# \mathrm{M} 7 \# 5$ & Fm7 & G7 & $\mathrm{G} \# \mathrm{M} 7$ & A\#dim 7 \\
\hline $\mathrm{C} \# \mathrm{mM} 7$ & $\mathrm{C} \# \mathrm{mM} 7$ & $\mathrm{D} \# \mathrm{~m} 7 \mathrm{~b} 5$ & $\mathrm{EM}_{7 \# 5}$ & $\mathrm{~F} \# \mathrm{~m} 7$ & $\mathrm{G} \# 7$ & $\mathrm{AM}_{7}$ & Bdim7 \\
\hline $\mathrm{DmM}_{7}$ & $\mathrm{DmM}_{7}$ & Em7b5 & FM7\#5 & $\mathrm{Gm} 7$ & A7 & $\mathrm{A} \# \mathrm{M} 7$ & $\operatorname{Cdim} 7$ \\
\hline $\mathrm{D} \# \mathrm{mM} 7$ & $\mathrm{D} \# \mathrm{mM} 7$ & Fm7b5 & $\mathrm{F} \# \mathrm{M} 7 \# 5$ & $\mathrm{G} \# \mathrm{~m} 7$ & A\#7 & $\mathrm{BM}_{7}$ & $\mathrm{C} \# \operatorname{dim} 7$ \\
\hline EmM7 & $\mathrm{EmM}_{7}$ & $\mathrm{~F} \# \mathrm{~m} 7 \mathrm{~b} 5$ & GM7\#5 & Am7 & B7 & $\mathrm{CM}_{7}$ & Ddim7 \\
\hline $\mathrm{FmM}_{7}$ & $\mathrm{FmM}_{7}$ & Gm7b5 & $\mathrm{G} \# \mathrm{M} 7 \# 5$ & A\# m7 & $\mathrm{C}_{7}$ & $\mathrm{C} \# \mathrm{M} 7$ & D\#dim 7 \\
\hline $\mathrm{F} \# \mathrm{mM} 7$ & $\mathrm{~F} \# \mathrm{mM} 7$ & $\mathrm{G} \# \mathrm{~m} 7 \mathrm{~b} 5$ & $\mathrm{AM}_{7 \# 5}$ & $\mathrm{Bm} 7$ & C\#7 & $\mathrm{DM}_{7}$ & Edim7 \\
\hline $\mathrm{GmM}_{7}$ & $\mathrm{GmM}_{7}$ & Am7b5 & $\mathrm{A} \# \mathrm{M} 7 \# 5$ & $\mathrm{Cm}_{7}$ & D7 & $\mathrm{D} \# \mathrm{M} 7$ & Fdim7 \\
\hline $\mathrm{G} \# \mathrm{mM}_{7}$ & $\mathrm{G} \# \mathrm{mM} 7$ & A\#m7b5 & $\mathrm{BM}_{7 \# 5}$ & $\mathrm{C} \# \mathrm{~m} 7$ & D\#7 & $\mathrm{EM} 7$ & $\mathrm{~F} \# \operatorname{dim} 7$ \\
\hline
\end{tabular}

\section{c. Pencarian Tingkatan Akor Minor Tangga} Nada Minor Melodis

Berdasarkan Tabel 11 tingkatan Akor minor melodis adalah :

AmM7-Bm7-CM7\#5-D7-E7-F\#m7b5-G\#m7b5

Menggunakan fungsi transposisi akor maka didapat : 
Tabel 17. Tingkatan Akor untuk Semua Akor Dasar Minor Melodis

\begin{tabular}{|c|c|c|c|c|c|c|c|}
\hline $\begin{array}{l}\text { NAMA } \\
\text { AKOR } \\
\text { (DASAR }\end{array}$ & \multicolumn{6}{|c|}{ TINGKATAN AKOR MINOR MELODIS } \\
\hline AmM7 & AmM7 & Bm7 & CM7\#5 & D7 & E7 & F\#m7b5 & G\#m7b5 \\
\hline A\#mM7 & A\#mM7 & Cm7 & C\#M7\#5 & D\#7 & F7 & F\#m7b5 & G\#m7b5 \\
\hline BmM7 & BmM7 & C\#m7 & DM7\#5 & E7 & F\#7 & Gm7b5 & Am7b5 \\
\hline CmM7 & CmM7 & Dm7 & D\#M7\#5 & F7 & G7 & G\#m7b5 & A\#m7b5 \\
\hline C\#mM7 & ImM7 & D\#m7 & EM7\#5 & F\#7 & G\#7 & Am7b5 & Bm7b5 \\
\hline DmM7 & DmM7 & Em7 & FM7\#5 & G7 & A7 & A\#m7b5 & Cm7b5 \\
\hline D\#mM7 & D\#mM7 & Fm7 & F\#M7\#5 & G\#7 & A\#7 & Bm7b5 & C\#m7b5 \\
\hline EmM7 & EmM7 & F\#m7 & GM7\#5 & A7 & B7 & Cm7b5 & Dm7b5 \\
\hline FmM7 & FmM7 & Gm7 & G\#M7\#5 & A\#7 & C7 & C\#m7b5 & D\#m7b5 \\
\hline F\#mM7 & F\#mM7 & G\#m7 & AM7\#5 & B7 & C\#7 & Dm7b5 & Em7b5 \\
\hline GmM7 & GmM7 & Am7 & A\#M7\#5 & C7 & D7 & D\#m7b5 & Fm7b5 \\
\hline G\#mM7 & G\#mM7 & A\#m7 & BM7\#5 & C\#7 & D\#7 & Em7b5 & F\#m7b5 \\
\hline
\end{tabular}

Berdasarkan hasil tersebut, terdapat masingmasing 12 akor dasar bersama tingkatan akornya pada setiap tangga nada minor asli, harmonis dan melodis. Data tersebut akan lebih memudahkan pemusik dalam memainkan sebuah lagu saat akor-akornya berubah menjadi lebih tinggi atau rendah sesuai dengan wilayah suara penyanyi. Dan sekaligus membantu pemain musik menentukan akor-akor yang tepat dalam memainkan alat musik, saat susunan tangga nada/akor-akor penyusun lagu berubah nada dasar.

\section{PENUTUP}

\subsection{Kesimpulan}

Susunan tangga nada mayor, minor asli, harmonis dan melodis dapat diperoleh menggunakan fungsi transposisi $T_{n}(x) \equiv(x+n \bmod 12)$, untuk $x=$ himpunan nada-nada pada tangga nada mayor, minor natural, harmonis dan melodis. Dimulai dari tangga nada mayor ditemukan keseluruhan susunan nada pada nada dasar C\#, D, D\#, E, F, F\#, G, G\#, A, A\#, dan B. Demikian juga untuk susunan tangga nada minor asli, harmonis dan melodis ditemukan keseluruhan susunan nada pada nada dasar A\#, B, C, C\#, D, D\#, E, F, F\#, G, dan G\#, untuk setiap tangga nada minor asli, harmonis dan melodis.

Selain itu, menggunakan fungsi transposisi yang sama, untuk $x$ himpunan akor minor natural, harmonis dan melodis, ditemukan tingkatan akor minor lainnya mulai dari tingkatan akor minor asli/natural baik dari tingkatan ke I sampai tingkatan ke VII pada setiap akor dasar A\#m, Bm, Cm, C\#m, Dm, D\#m, Em, Fm, F\#m, Gm, dan G\#m. Demikian juga untuk tingkatan akor harmonis dan melodis didapat keseluruhan tingkatan akor mulai dari akor dasar $\mathrm{A} \# \mathrm{mM}_{7}, \mathrm{BmM}_{7}, \mathrm{CmM}_{7}, \mathrm{C} \# \mathrm{mM}_{7}, \mathrm{DmM}_{7}$, $\mathrm{D} \# \mathrm{Mm} 7, \quad \mathrm{EmM} 7, \quad \mathrm{FmM} 7, \mathrm{~F} \# \mathrm{mM} 7, \mathrm{GmM} 7$, dan $\mathrm{G} \# \mathrm{mM} 7$.
Hasil penelitian ini akan lebih memudahkan seorang pemusik dalam memainkan melodi dan akorakor penyusun sebuah lagu, bila nada dasarnya berpindah menjadi lebih tinggi atau rendah. Begitu juga sang penyanyi akan lebih mudah untuk menentukan nada dasar yang cocok pada sebuah lagu yang akan dinyanyikan.

\subsection{Saran}

Penulis dapat memberikan beberapa saran untuk penelitian lebih lanjut yaitu sebagai berikut :

1. Menerapkan rumus fungsi transposisi pada pencarian susunan tangga nada pentatonis atau tangga nada lainnya.

2. Menerapkan rumus fungsi transposisi akor untuk mencari tingkatan akor pada tangga nada pentatonis atau tangga nada lainnya.

3. Menggunakan aplikasi matematika seperti matlab untuk menghitung transposisi tangga nada dan akor.

\section{REFERENSI}

[1] Fiore, Thomas M. 2009. Music and Mathematics. University Of Michigan, Michigan

[2] Prakoso, Y. A., Hannifah, S. Maizora. 2017. Pengaruh Musik Klasik Terhadap Hasil dan Aktivitas Belajar Matematika Siswa Kelas VII di SMPN 2 Kota Bengkulu (Studi Ekperimen di SMPN 2 Sawah Lebar Kota Bengkulu). Jurnal Penelitian Pembelajaran Matematika Sekolah (JP2MS) 1(1)

[3] Sa'diyah, H. 2008. Penerapan Fungsi Transposisi Akor Pada Perpindahan Tangga Nada. [skripsi], Jurusan Matematika Fakultas Sains dan Teknologi Universitas Islam Negeri, Malang.

[4] Sri Mudjilah, Hanna. 2010. Teori Musik 1. FBS UNY, Yogyakarta

[5] Wulandari, I. N. dan D. Juniati. 2017. Penerapan Dimensi Fraktal Untuk Klasifikasi Laras Pada Musik Gamelan. Jurnal Ilmiah Matematika 3(6)

\section{Yuanita Wajongkere (juanitawayongkere93@gmail.com)}

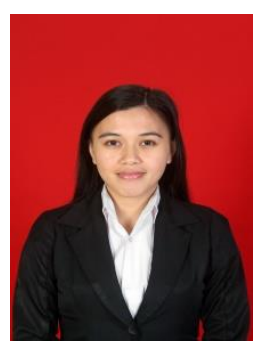

Lahir di Desa Tincep, Kecamatan Sonder, Kabupaten Minahasa, Provinsi Sulawesi Utara pada tanggal o7 Juni 1993. Menempuh pendidikan tinggi Jurusan Matematika, FMIPA, Universitas Sam Ratulangi Manado. Tahun 2018 adalah tahun terakhir ia menempuh studi. Makalah ini merupakan hasil penelitian skripsinya yang dipublikasikan. 
Yohanes A. R. Langi (yarlangi@unsrat.ac.id)

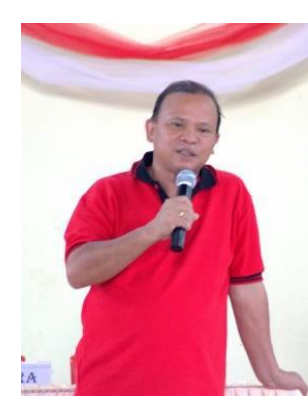

Pada tahun 1994, memperoleh gelar sarjana di Departemen Matematika, Fakultas MIPA Universitas Kristen Tomohon. Gelar magister bidang Biometrika Hutan diperoleh dari Departemen Biometrika, Institut Pertanian Bogor, pada tahun 2007. Menjadi dosen di departemen Matematika, FMIPA, Universitas Sam Ratulangi Manado sejak tahun 2005 sampai sekarang dengan bidang keahlian yang ditekuni diantaranya; Proses Stokastik, Perancangan Percobaan, dan Biometrika.

\section{Jullia Titaley (july_titaley@unsrat.ac.id)}

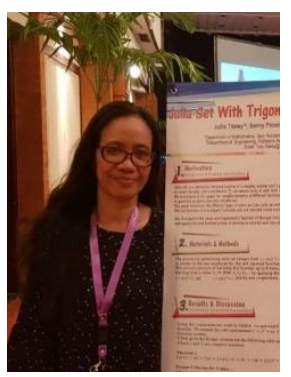

Pada tahun 1997, memperoleh gelar sarjana di Program Studi Matematika, Universitas Pattimura Ambon. Gelar Magister Sains diperoleh dari Universitas Gajah Mada pada tahun 2001. Menjadi dosen di Jurusan Matematika, FMIPA, Universitas Sam Ratulangi Manado sejak tahun 2002 sampai sekarang dengan bidang keahlian yang ditekuni diantaranya; Analisis, Aljabar, dan Geometri. 